\title{
Comparison of Tensile Strength of Different Carbon Fabric Reinforced Epoxy Composites
}

\author{
Jane Maria Faulstich de Paiva ${ }^{\mathrm{a}, \mathrm{b} *}$, Sérgio Mayer ${ }^{\mathrm{c}, \mathrm{d}}$, Mirabel Cerqueira Rezende ${ }^{\mathrm{a} *}$ \\ à Divisão de Materiais, AMR/IAE, Centro Técnico Aeroespacial-CTA, \\ Praça Marechal-do-Ar Eduardo Gomes, 50, Vila das Acácias, \\ 12228-904 São José dos Campos - SP, Brazil \\ ${ }^{\mathrm{b}}$ UNISAL, Centro Universitário Salesiano de São Paulo, \\ Engenharia Ambiental, Unidade de Americana - SP, Brazil \\ 'Departamento de Aeronáutica e Mecânica, ITA, Centro Técnico Aeroespacial-CTA, \\ São José dos Campos - SP, Brazil \\ ${ }^{\mathrm{d} E m p r e s a ~ B r a s i l e i r a}$ de Aeronáutica - EMBRAER, São José dos Campos - SP, Brazil
}

Received: December 2, 2004; Revised: December 2, 2005

\begin{abstract}
Carbon fabric/epoxy composites are materials used in aeronautical industry to manufacture several components as flaps, aileron, landing-gear doors and others. To evaluate these materials become important to know their mechanical properties, for example, the tensile strength. Tensile tests are usually performed in aeronautical industry to determinate tensile property data for material specifications, quality assurance and structural analysis. For this work, it was manufactured four different laminate families (F155/PW, F155/HS, F584/PW and F584/HS) using pre-impregnated materials (prepregs) based on $\mathrm{F} 155^{\mathrm{TM}}$ and $\mathrm{F} 584^{\mathrm{TM}}$ epoxy resins reinforced with carbon fiber fabric styles Plain Weave (PW) and Eight Harness Satin (8HS). The matrix F155 ${ }^{\mathrm{TM}}$ code is an epoxy resin type DGEBA (diglycidil ether of bisphenol A) that contains a curing agent and the $\mathrm{F} 584^{\mathrm{TM}}$ code is a modified epoxy resin type. The laminates were obtained by handing lay-up process following an appropriate curing cycle in autoclave. The samples were evaluated by tensile tests according to the ASTM D3039. The F584/PW laminates presented the highest values of tensile strength. However, the highest modulus results were determined for the $8 \mathrm{HS}$ composite laminates. The correlation of these results emphasizes the importance of the adequate combination of the polymeric matrix and the reinforcement arrangement in the structural composite manufacture. The microscopic analyses of the tested specimens show valid failure modes for composites used in aeronautical industry.
\end{abstract}

Keywords: composites, epoxy resin, carbon fibers, tensile test

\section{Introduction}

Carbon fabric reinforced polymeric composites are very used for manufacturing components as flaps, aileron, landing-gear doors, and other artifacts used in aeronautical industry ${ }^{1,2}$. Additionally, the composites can be used in other areas like home construction, navy, automotive and sport industries ${ }^{3,4}$.

In general, aeronautical polymeric composites are classified as advanced and present continuous fiber reinforcement (for example, carbon, glass or aramide) of high-modulus or high-strength embedded in a thermoset or thermoplastic polymeric matrix. The appropriate performance of these composites during use is mainly related to their mechanical properties and thermal resistance as a result of the adequate combination of reinforcement (tapes or fabrics), polymeric matrix and processing technique $\mathrm{e}^{2,5}$.

Polymeric composites reinforced with carbon reinforcements show mechanical properties similar or higher than the conventional metallic materials, because an advanced polymeric composite presents high strength-to-weight and stiffness-to-weight ratios ${ }^{2,5,6}$. In addition, the polymeric composites present higher fatigue strength and higher corrosion resistance.

Among the polymeric matrices, the epoxy resins (thermoset polymer type) are very used in aeronautical area, because they generally attend the mechanical strength, chemical resistance and service temperature requirements ${ }^{7,8}$. The epoxy resin also allows modifications in its chemical structure depending on the required application.

In the last years pre-impregnated (prepreg) material has been used to manufacture polymeric composites in aeronautical industries. The advantage of using prepreg is its tight relation between reinforcement and polymeric matrix (usually 60:40 (v:v)), respectively, for thermoset prepregs) attending several requirements for manufacturing structural composite components ${ }^{1,4-9-11}$.

Another important advantage presented by the prepregs is that this intermediate material is available as tape or fabric, which allows to adjust the reinforcement positioning, tickness, layer number and orientation in the molding, according to the mechanical efforts that the final component will be submitted. This material favors also an easy and clean manufacture of components with complex geometries ${ }^{12}$.

Despite the several advantages of the polymeric composites over the metallic materials, the former is more susceptible to mechanical damages when they are subjected to great efforts of tension, compression and impact, which can lead to interlayer delamination ${ }^{9,13-15}$. With further application of external load, the delamination propagates through the interlayers leading to catastrophic failure of the composite structure ${ }^{16}$.

Damage tolerance of polymeric thermoset composites can be enhanced by improving interlaminar properties by toughening the 
matrix with thermoplastic polymers and/or elastomer modifiers, and also by reinforcing the matrix with several rearrangements of the fibers ${ }^{16,17}$.

The modification of epoxy matrix with thermoplastic polymers and/or elastomers is a tendency of the aeronautical industry, aiming to reduce the mechanical damage of polymeric composites by impact loads ${ }^{12,18}$. So, the use of modified polymeric matrix in the composite manufacture requires a systematic evaluation of the mechanical properties. In this work, laminate composites with modified matrices were evaluated by tensile tests according to the aeronautical industry requirements.

The tensile tests are used to determine both strength and modulus values to be used in component projects and also to verify technical specifications and quality assurance of projects. The fracture surfaces, resultant of the tests, are used to support the failure mode analysis ${ }^{19,20}$. The literature shows that these parameters have been evaluated involving the epoxy composites characterization ${ }^{15,21,22}$.

In this work, it was used rectangular specimens of polymeric composites with end-tabs in accordance to ASTM D303920. Generally, rectangular specimens are required for the composite material characterization, because the "dog-bone" type tends to split in the region where the width changes. Still the grips of tension test frame introduce large stress concentration in the specimen. To minimize this effect, tabs with tapered ends must be bonded on each side of the specimen, because the tensile test can cause tension concentration with shear load.

The tensile strength of specimens with the reinforcement oriented at $0^{\circ}$ is governed by the tensile strength of the fibers, while for the $90^{\circ}$ ones the specimens fail by crack propagation through the matrix and/or the fiber/matrix interface ${ }^{19,21}$. When fabric reinforcement is used it can occurs different failure mechanisms. The influence of the reinforcement orientation on the compression after impact strength of the carbon fabric/epoxy composites is related by Paiva et al. ${ }^{18}$.

This work shows a study involving the tensile strengths of four different composite laminates, using two types of epoxy matrix (F155 and F584) reinforced with two types of carbon fabrics (PW and 8HS). Failure modes of specimens tested under tensile test were also classified in according with ASTM D3039-0020 recommendation.

\section{Experimental}

\subsection{Composites molding}

For molding the studied polymeric composites it was used prepregs based on epoxy matrices (F155 and F584 codes) and carbon fiber fabric reinforcements $\left(0 / 90^{\circ}\right)$ with Plain Weave (PW) and Eight Harness Satin (8HS) arrangement types. The $\mathrm{F} 155^{\mathrm{TM}}$ is an epoxy resin DGEBA (diglycidil-ether of bisphenol-A) type and F584 ${ }^{\mathrm{TM}}$ is a modified epoxy resin combined with elastomeric novel converters to give elongation when the fibers are strained. The F584 ${ }^{\mathrm{TM}}$ modified epoxy resin presents medium toughness and impact resistance ${ }^{12}$. The supplier (Hexcel Composites) does not reveal more details about the prepregs, which justify that more detailed technical information about the modified epoxy formulations is restricted.

The manufacture of the four laminate composite families (F155/ PW, F155/HS, F584/PW and F584/HS) was carried out by manual lamination process positioning the prepreg sheets in a metallic mold. The molding process used an autoclave system under pressure of $0.70 \mathrm{MPa}$ and vacuum of $0.08 \mathrm{MPa}$. For the F155, it was used a curing cycle with a heating rate of $2.5 \pm 0.2{ }^{\circ} \mathrm{C} \cdot \mathrm{min}^{-1}$ up to $121{ }^{\circ} \mathrm{C}$, holding at this temperature at least $90 \mathrm{~min}$. For the $\mathrm{F} 584$ prepreg it was used a curing cycle with a heating rate of $2.5 \pm 0.2^{\circ} \mathrm{C} \cdot \mathrm{min}^{-1}$ up to $177^{\circ} \mathrm{C}$, holding at this temperature for a minimum period of 120 minutes. All processed laminates (F155/PW, F155/HS, F584/PW and F584/HS) presented $60 \pm 1 \%(\mathrm{v} / \mathrm{v})$ of carbon fiber reinforcement. The resin and reinforcement contents were determined by acid digestion method according to ASTM D3171-76 ${ }^{23}$. Thickness of the laminates was 2-3 mm attending the ASTM D303920.

\subsection{Ultrasonic inspection}

After molding, all laminates were inspected by ultrasound technique adapted with water squirt. For inspection it was used an ultrasonic failure detector Reflectoscope S80 with a 0.750 ”, $5 \mathrm{MHz}$ transmitter type Automation X19625 and a receiver type Automation X19267. The laminate plates were mounted midway between probes that were carefully aligned to maximize the transmitted signal. The probes were transported by an Automation US640 system that generates a quantized $\mathrm{C}$-scan record of the laminate.

\subsection{Tensile test}

The tensile tests were carried out in accordance with ASTM D303920, using a minimum of twelve specimens (dimensions: $250 \mathrm{~mm}$ of length $\times 25 \mathrm{~mm}$ of width $\times 2-3 \mathrm{~mm}$ of thickness) for each laminate family (F155/PW, F155/HS, F584/PW and F584/HS). The specimens were prepared by bonding end-tabs of glass fibers/epoxy laminate. This procedure resulted in available area of $130 \mathrm{~mm}^{2}$ of the specimen for the tensile test. Figure 1 shows, respectively, the specimens of F155/8HS and F584/8HS laminates.

The tensile tests were performed in an universal testing machine MTS, model 744, with hydraulic grip and MTS 632 12C-20 extensometer, at constant cross-speed of approximately $1.3 \mathrm{~mm} \cdot \mathrm{min}^{-1}$, at room temperature.

To calculate the tensile strength it was used the equation ${ }^{20}$ :

$\sigma=\mathrm{P}_{\max } / \mathrm{A}$

where:

$\sigma=$ tensile strength, MPa

$\mathrm{P}_{\max }=$ maximum load prior to failure, $\mathrm{N}$

$\mathrm{A}=$ average cross-sectional area, $\mathrm{m}^{2}$

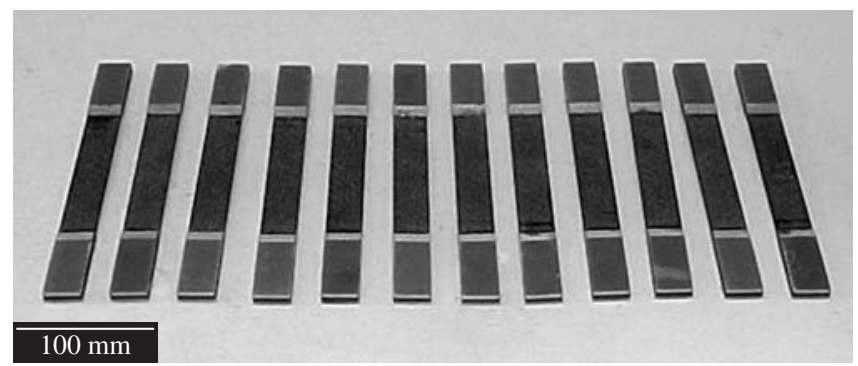

(a)

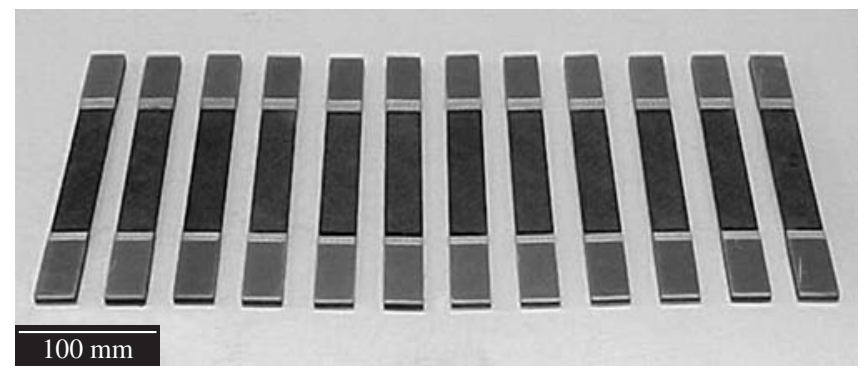

(b)

Figure 1. Specimens of laminates for tensile tests: a) F155/8HS; and b) F584/8HS composites. 


\subsection{Specimen inspection}

After the tensile tests, the specimens were photographed and the failure modes were analyzed in accordance with the type and the location of the damages attending the ASTM D3039-0020 (Figure 2). To facilitate the interpretation of the typical failure modes they are codified $^{20}$ in sequence based on characteristics of type, area, local, etc., as shown in Tables 1, 2 and 3 .

\subsection{Stereoscopy analysis}

After classification of the failure modes the specimens were analyzed in a Zeiss stereoscopy equipment, Stemi SV11 model.

\section{Results and Discussion}

After molding, the ultrasonic analyses of the inspected laminates presented the attenuation values depicted in Table 4 and the images showed in Figure 3. In accordance with the scale in the right side, the
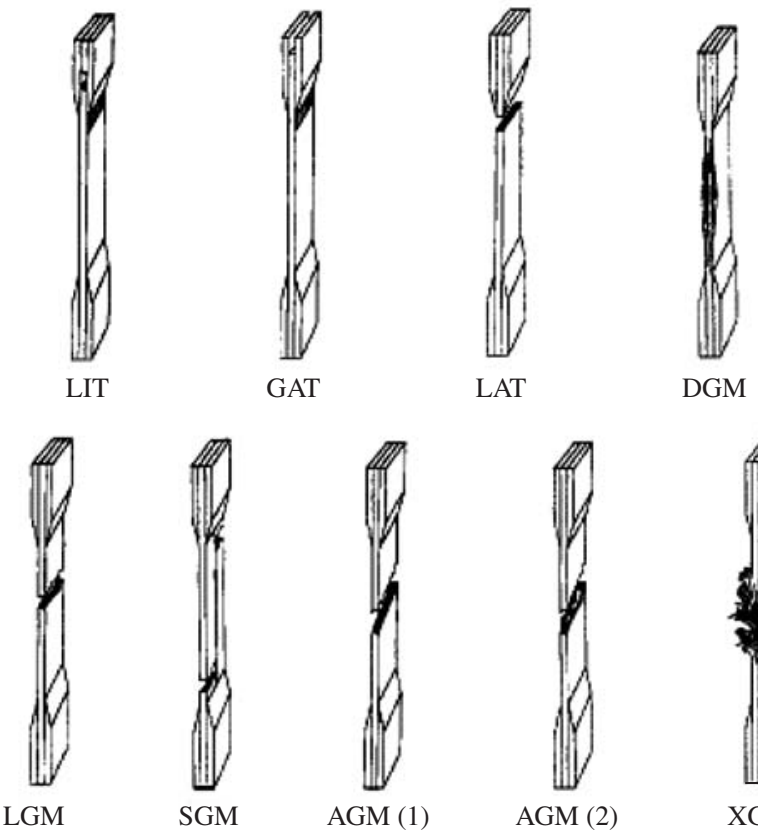

Figure 2. Representation of some typical failure modes in tensile tests of composites $^{20}$.

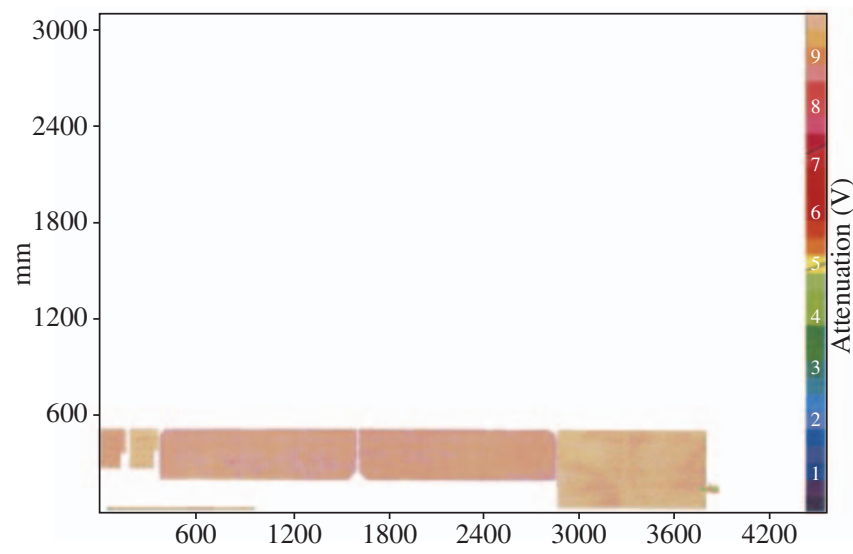

Figure 3. Typical C-Scan ultrasonic images after laminates molding. non-occurrence of defects is related to the superior part (originally in orange color), corresponding to the attenuation value of nearly 9. The middle part (originally in green color) indicates the occurrence of defects as voids, delamination, debonding fiber-matrix, and others, corresponding to attenuation values smaller than 5 . The inferior part (originally in blue color) reveals more intense defects with attenuation value equals 1 .

The analysis of the original archives of the C-scan ultrasonic images shows that the four laminate families present the orange

Table 1. Codes related to the first characteristic ("type") of the failure mode $^{20}$.

\begin{tabular}{ll}
\hline Failure Type & Code \\
\hline Angled & $\mathrm{A}$ \\
Edge Delamination & $\mathrm{D}$ \\
Grip/tab & $\mathrm{G}$ \\
Lateral & $\mathrm{L}$ \\
Multi-mode & $\mathrm{M}(\mathrm{xyz})$ \\
Long Splitting & $\mathrm{S}$ \\
Explosive & $\mathrm{X}$ \\
Other & $\mathrm{O}$ \\
\hline
\end{tabular}

Table 2. Codes related to the second characteristic ("area") of the failure mode $^{20}$

\begin{tabular}{lc}
\hline Failure Area & Code \\
\hline Inside grip/tab & $\mathrm{I}$ \\
At grip/tab & $\mathrm{A}$ \\
$<1 \mathrm{~W}$ from grip/tab & $\mathrm{W}$ \\
Gage & $\mathrm{G}$ \\
Multiple Areas & $\mathrm{M}$ \\
Various & $\mathrm{V}$ \\
Unknown & $\mathrm{U}$ \\
\hline
\end{tabular}

Table 3. Codes related to the third characteristic ("local") of the failure mode ${ }^{20}$.

\begin{tabular}{lc}
\hline Failure Location & Code \\
\hline Bottom & $\mathrm{B}$ \\
Top & $\mathrm{T}$ \\
Left & $\mathrm{L}$ \\
Right & $\mathrm{R}$ \\
Middle & $\mathrm{M}$ \\
Various & $\mathrm{V}$ \\
Unknown & $\mathrm{U}$ \\
\hline
\end{tabular}

Table 4. Attenuation values by ultrasonic inspection of the laminates after molding.

\begin{tabular}{cc}
\hline Laminate & Attenuation $(\mathrm{V})$ \\
\hline F155/PW & 8.33 to 9.67 \\
F155/8HS & 8.67 to 9.33 \\
F584/PW & 8.00 to 9.67 \\
F584/8HS & 8.67 to 9.67 \\
\hline
\end{tabular}


color, i.e., the composite laminates presented good quality, without fabrication defects as delamination, voids, cracks, etc.

Table 5 presents the average results of tensile strength and modulus values of twelve specimens tested for each laminate family. The results show that the modified F584-epoxy matrix laminates present higher mechanical properties when compared to the F155-epoxy ones. The F584/PW family presented the highest tensile strength value (approximately $1185 \mathrm{MPa}$ ) and the F584/8HS the highest tensile modulus (approximately $72 \mathrm{GPa}$ ). These results suggest that the used toughen modifier presented a good compatibility with both F584 epoxy matrix and carbon fiber reinforcement. This good compatibility has probably improved the interfacial adhesion between the components and, consequently, the tensile property of the F584 laminates.

Considering the fiber rearrangements, it is observed that the PW fabric type shows an increase of the tensile strength when compared with the 8HS type, for both epoxy matrices studied. This tendency increases when the PW reinforcement is combined with the modified F584 epoxy matrix. Probably, this behavior is related to the F584 matrix toughness that results in an appropriate elongation when the carbon fibers are strained. However, these samples showed a contrary behavior for the tensile modulus property, where the 8HS arrangement showed the highest values for the two epoxy matrices.

Tensile strength results attend the requirements for qualification and conformance assurance of the aeronautical industry. According to MEP $15-022^{24}$, the medium tensile strength values for composites reinforced with fabric $\left(0 / 90^{\circ}\right)$ are $689 \mathrm{MPa}$. For tensile modulus, the range obtained is between $58 \mathrm{GPa}$ to $79 \mathrm{GPa}$. For comparison, composites reinforced with tape (unidirectional) have a tensile strength of approximately $1700 \mathrm{MPa}$, when tested in the direction of $0^{\circ 24}$. The literature reports that epoxy matrix reinforced with continuous unidirectional carbon fiber presents approximately $1450 \mathrm{MPa}$ of tensile strength when tested in the direction of $0^{\circ}$ and $62 \mathrm{MPa}$ when tested in the direction of $90^{\circ 2}$.

In general, the main advantage of use fabric as reinforcement in composite is that the laminates have balanced properties in orientations of $0^{\circ}$ and $90^{\circ}$. However, the tensile strength and modulus of fabric-reinforced composites are lower than the unidirectional fiber (tape) reinforced composites ${ }^{2}$.

Table 5. Results of tensile tests of the composites.

\begin{tabular}{lccrl}
\hline Composite & $\begin{array}{c}\text { Tensile } \\
\text { Strength } \\
(\mathrm{MPa})\end{array}$ & $\begin{array}{c}\text { Modulus } \\
(\mathrm{GPa})\end{array}$ & Failure Modes \\
\hline F155/PW & $950.5 \pm 24.7$ & $57.8 \pm 3.5$ & LGM & $(5$ specimens $)$ \\
& & & LIT & $(2$ specimens $)$ \\
& & & LMV & $(2$ specimens $)$ \\
& & & LAT & $(2$ specimens $)$ \\
F155/8HS & $810.0 \pm 36.6$ & $67.8 \pm 6.0$ & LAB & $(1$ specimens $)$ \\
& & & LGM & $(3$ specimens $)$ \\
& & & LIT & $(2$ specimens $)$ \\
F584/PW & $1185.4 \pm 51.4$ & $65.6 \pm 4.3$ & LIB & $(2$ specimens $)$ \\
& & & LGT & $(5$ specimens $)$ \\
& & & LGM & $(2$ specimens $)$ \\
& & & LIT & $(2$ specimens $)$ \\
F584/8HS & $985.9 \pm 62.7$ & $71.5 \pm 0.3$ & LGM & $(4$ specimens $)$ \\
& & & LGB & $(3$ specimens $)$ \\
& & & LIB & $(3$ specimens $)$ \\
& & & LAB & $(2$ specimens $)$ \\
\hline
\end{tabular}

Lower tensile strength values of fabric reinforced polymeric composites are related to the bi-directional orientation and the undulations of the roving in the fabric, due to the woven arrangements (or fabric weave patterns). Still, during the tensile test the woven arrangements tend to alignment with the effort direction, resulting in microcracks in the polymeric matrix of the composite ${ }^{2}$.

To minimize these events it can be used different types of fabric and arrangements. The tensile properties can also be modified by changes in the lamination process and/or sequence of the layers of the fabrics.

Figures 4 to 7 show typical specimens tested in tensile, which presented valid failure mode, classified in accordance with ASTM D3039-00 ${ }^{20}$ (Figure 2) and depicted in Tables 1, 2 and 3.

After the tensile tests all specimen/tab bonded regions of the specimens were evaluated and it was verified no occurrence of failure by shear and/or debonding in the interface between laminate/tab. Some specimens presented fracture near to the tabs as classified in the ASTM D3039-00 ${ }^{20}$ and cited in Tables 1, 2 and 3, but no specimens showed adhesion failure. Therefore, all the occurred failure modes are considered valid and used to calculate the tensile strength and modulus of the tested specimens.

Figures 8 to 11 show micrographs obtained by stereoscopy analyses of the specimens fractured in tensile tests. It is observed

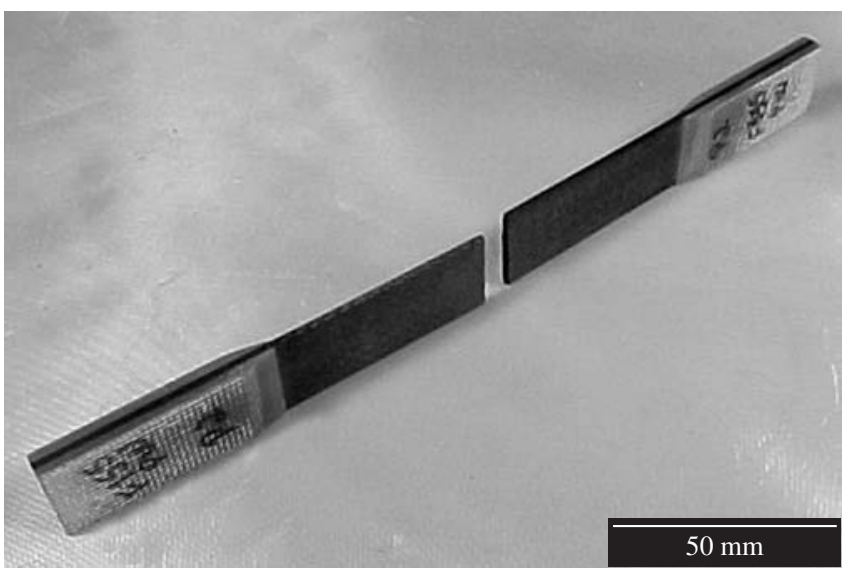

(a)

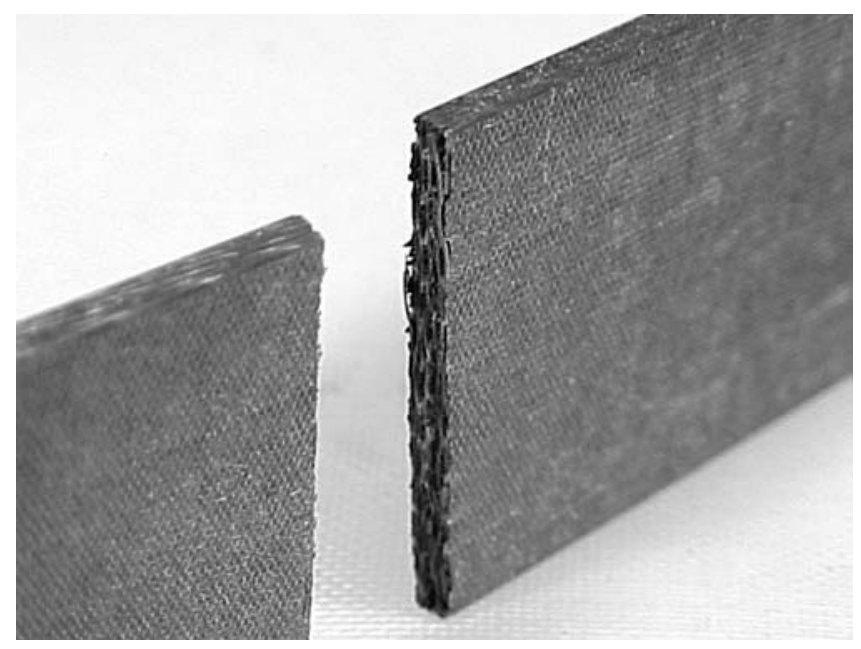

(b)

Figure 4. F155/PW laminate: a) specimen tested; and b) detail of the failure mode type LGM (Lateral Gage Middle). 


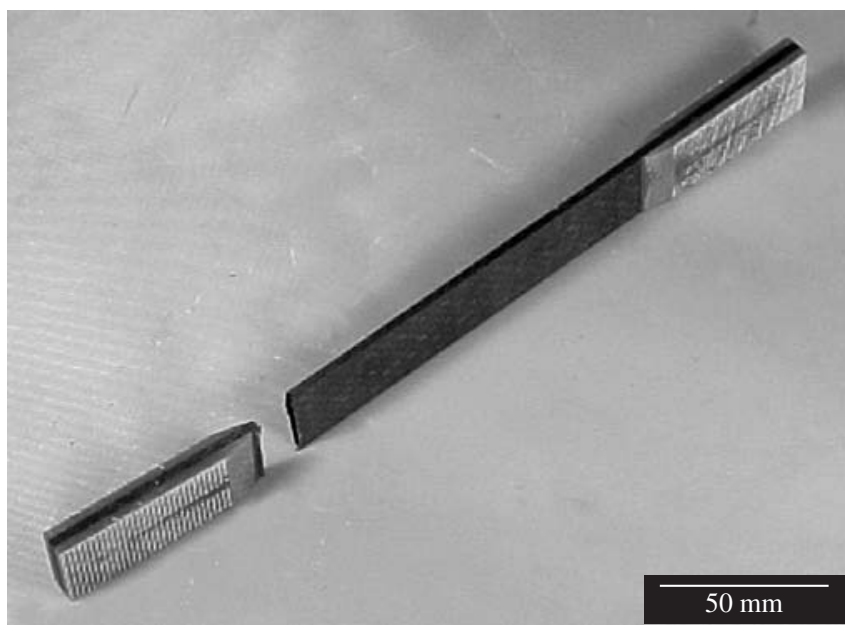

(a)

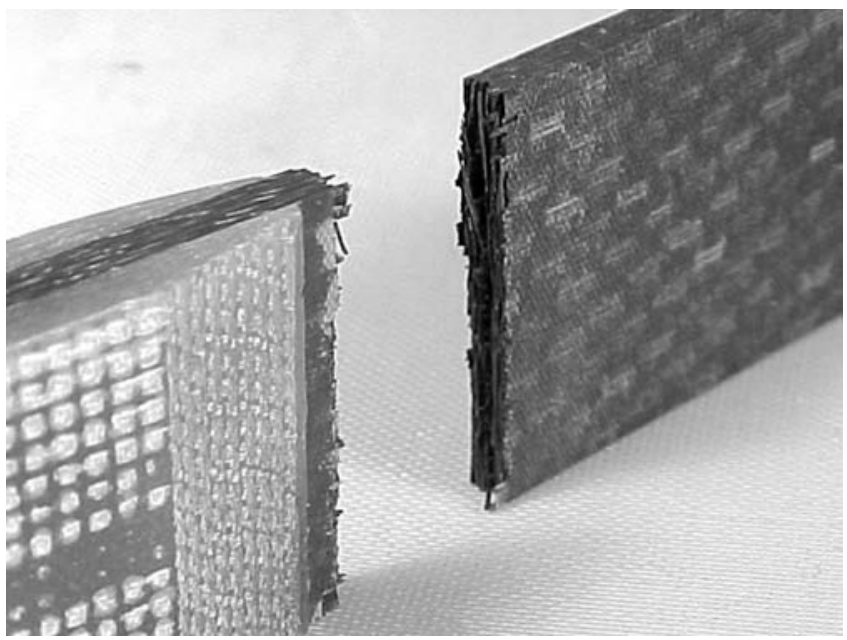

(b)

Figure 5. F155/8HS laminate: a) specimen tested; and b) detail of the failure mode type LAB (Lateral At grip/tab Bottom).

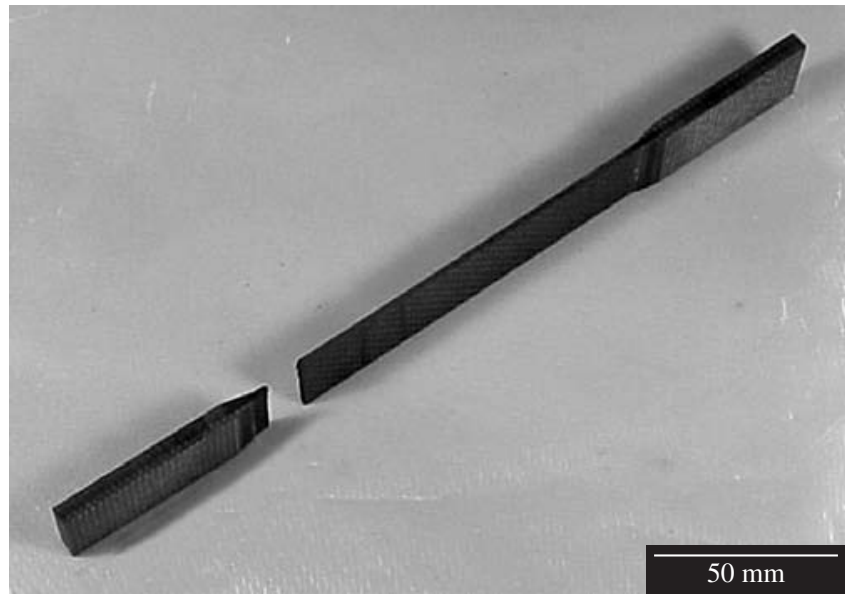

(a)

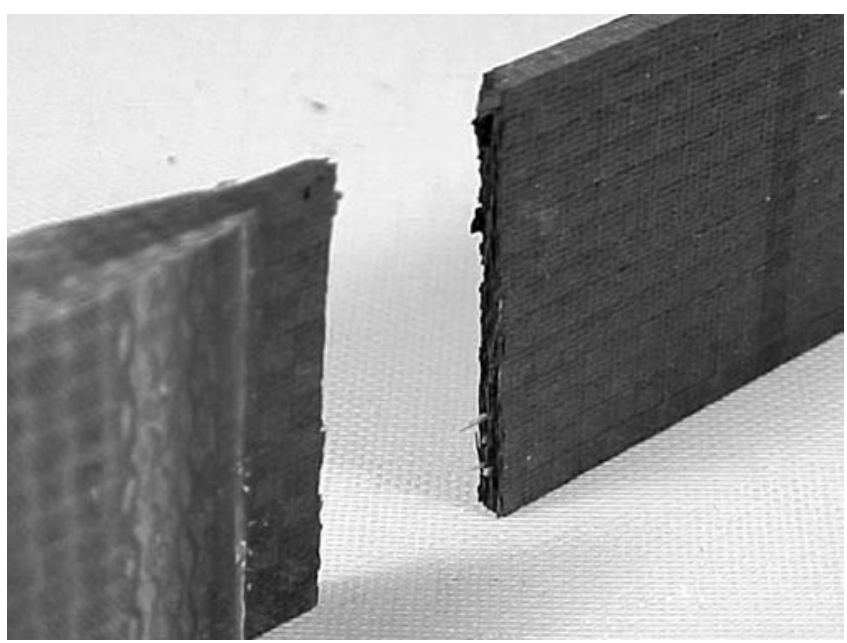

(b)

Figure 6. F584/PW laminate: a) specimen tested; and b) detail of the failure mode type LGB (Lateral Gage Bottom).

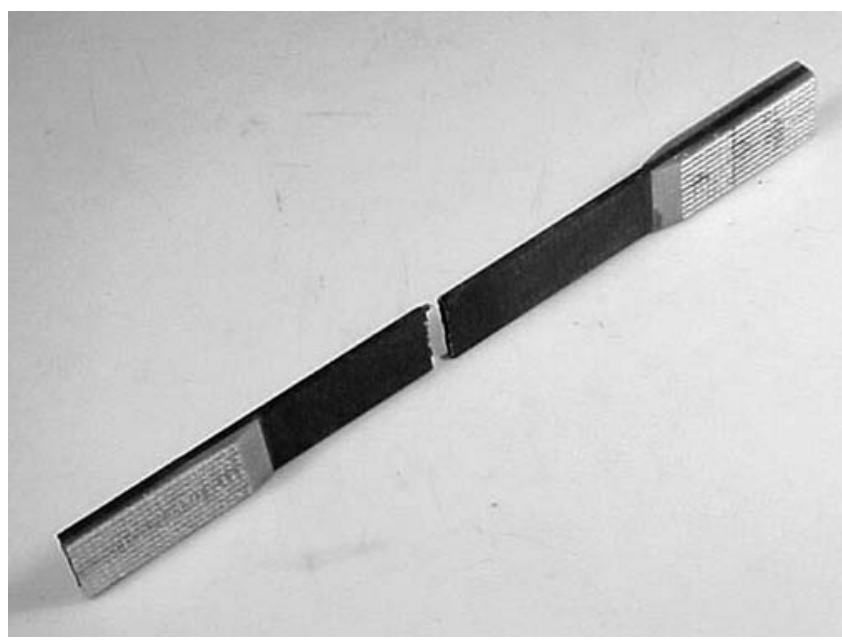

(a)

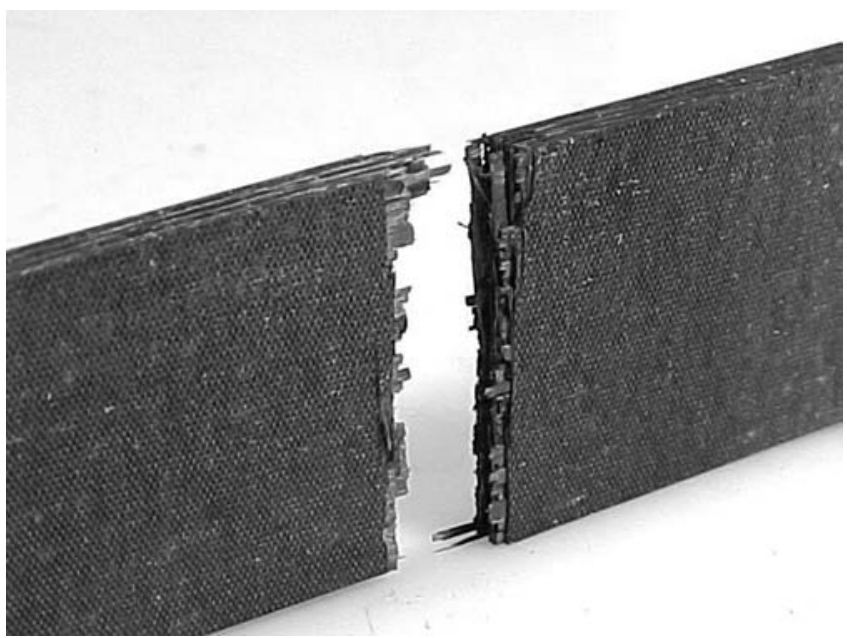

(b)

Figure 7. F584/8HS laminate: a) specimen tested; and b) detail of the failure mode type LGM (Lateral Gage Middle). 


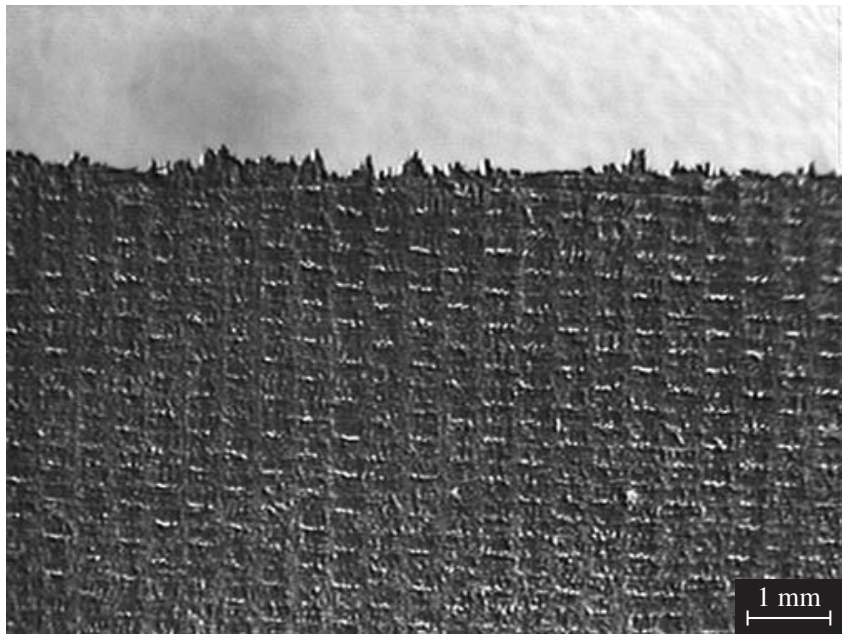

Figure 8. F155/PW specimen after tensile test, (10x).

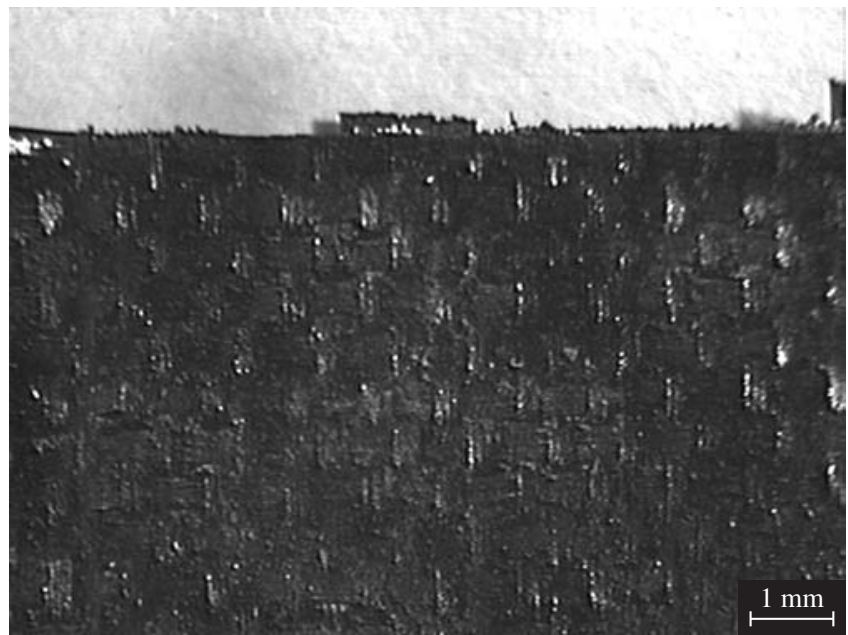

Figure 9. F584/PW specimen after tensile test, (10x).

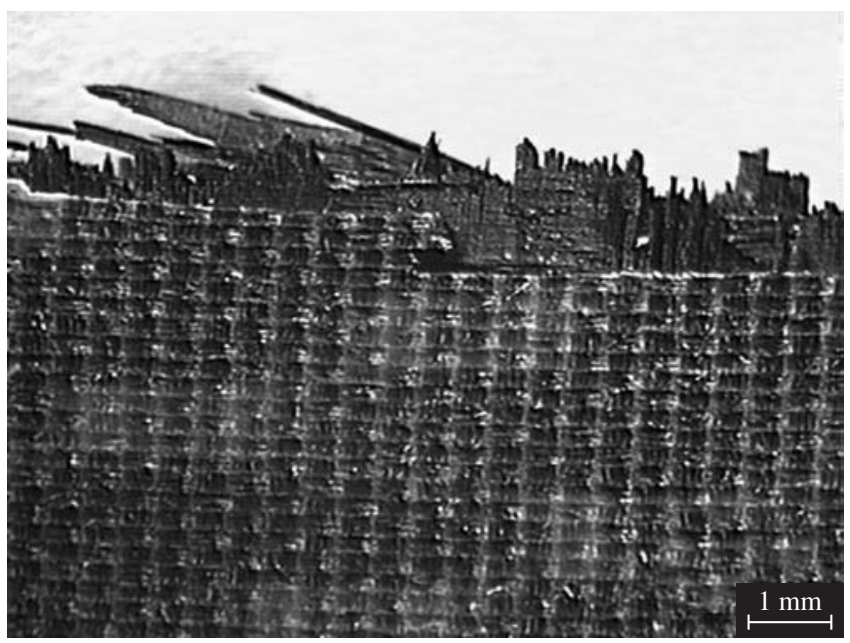

Figure 10. F155/8HS specimen after tensile test, (10x).

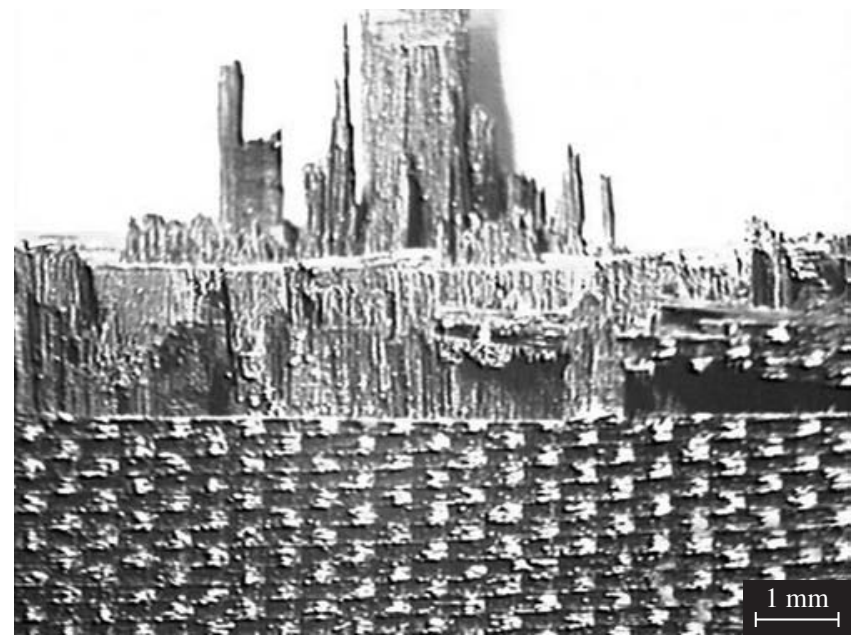

Figure 11. F584/8HS specimen after tensile test, (10x).

that the laminates presented total failure in spite of the different arrangements of the warp and fill of the carbon fabrics. The main difference observed is that the composites reinforced with PW ("Plain Weave") fabric present fractures more linear (Figures 8 and 9) called simple and fragile fractures ${ }^{25,26}$. The composites reinforced with $8 \mathrm{HS}$ ("Eight Harness Satin") fabric present fragile fracture with several planes called "multi-stepped fracture" ${ }^{25}$. This behavior is related to the rearrangements of the warp and fill of the fabric. It is observed that the 8HS type facilitates the crack propagation (Figures 10 and 11), resulting in a more rapid total failure of the composite laminate and causing a slight decreasing in the tensile strength of the laminate reinforced with this fabric.

\section{Conclusions}

All failure modes were classified according to the ASTM D3039-00 and they are considered valid for aeronautical industry and can be used to calculate the tensile strength and the modulus of the tested specimens.

The tensile test results showed that the laminates with modified F584-epoxy matrix present higher mechanical properties when compared to the F155-epoxy matrix. The F584/PW family presented the highest tensile strength value (approximately $1185 \mathrm{MPa}$ ) and the F584/8HS the highest modulus (approximately $72 \mathrm{GPa}$ ). These results suggest that the used modifier presented a good compatibility with both F584 epoxy matrix and carbon fiber reinforcement, with the advantage of increasing the tensile property of the F584 matrix.

In relation to the fabric rearrangements, the PW type showed an increase of the tensile strength when compared with 8HS type, for both epoxy matrices studied. However, for the modulus property, the samples showed a contrary behavior, where the $8 \mathrm{HS}$ arrangement showed the highest values for two epoxy matrices. Microscopic analyses revealed clearly that the carbon fiber rearrangement influences over the general aspect of the fractured laminates.

The correlation of these results emphasizes the importance of an adequate combination of polymeric matrix and reinforcement arrangement in the structural composite manufacture, aiming the end use of the processed component. 


\section{Acknowledgments}

The authors acknowledge the financial support received from FAPESP and CNPq under grants 02/02057-5 and 303528/2003-6, respectively. The authors are grateful to Hexcel Composites and EMBRAER for supplying the test material.

\section{References}

1. Cândido GM, Almeida SFM, Rezende MC. Processamento de laminados de compósitos poliméricos avançados com bordas moldadas. Polímeros: Ciência e Tecnologia. 2000; 10(1):31-41.

2. Schwartz MM. Composite Materials: Properties, Nondestructive Testing, and Repair. v. 1. New Jersey, USA. Prentice-Hall Inc; 1997.

3. Buehler FU, Seferis JC. Effect of reinforcement and solvent content on moisture absorption in epoxy composite materials. Composites Part A. 2000; 31(7):741-748.

4. Hayes BS, Gilbert EN, Seferis JC. Scaling complications of dual temperature cure resin prepreg systems in airplane part manufacture. Composites Part A Applied Science and Manufacturing. 2000; 31(7):717-725.

5. Pilato LA, Michno MJ. Advanced Composite Materials. Berlin, Germany. Springer Verlag Berlin Heidelberg; 1994.

6. Baker AA, Callus PJ, Georgiadis S, Falzon PJ, Dutton SE, Leong KH. An affordable methodology for replacing metallic aircraft panels with advanced composites. Composites: Part A. 2002; 33(5):687-696.

7. Penn LS, Wang H. Epoxy resins. In: Peters ST, editor. Handbook of Composites. 2 ed. Chapman \& Hall, Great Britain; 1998.

8. Shim SB, Seferis JC, Eom YS, Shim YT. Thermal characterization and comparison of structural prepregs with different cure temperatures. Thermochimica Acta. 1997; 291(1-2):73-79.

9. Moura MFSF, Marques AT. Prediction of low velocity impact damage in carbon-epoxy laminates. Composites Part A. 2002; 33(5):361-368.

10. Wingard CD. Characterization of prepreg and cured epoxy/fiberglass composite material for use in advanced composite piping systems. Thermochimica Acta. 2000; 357-358: 293-301.

11. Choi, HS, Ahn KJ, Nam JD, Chun HJ. Hygroscopic aspects of epoxy/ carbon fiber composite laminates in aircraft environments. Composites: Part A. 2001; 32:709-720.

12. Hexcel Composites. Available from: http://www.hexcel.com; 2003 Nov. 11.

13. Ding YQ, Yan Y, McIlhagger R. Effect of impact and fatique loads on the strength of plain weave carbon-epoxy composites. Journal of Materials Processing Technology. 1995; 55:58-62.
14. Gao S-L, Kim JK. Cooling rate influences in carbon fibre/PEEK composites. Part III: impact damage performance. Composites Part A. 2001; 32: 775-785.

15. Mayer S. Influência do condicionamento ambiental na resistência à tração de laminados de compósitos poliméricos reparados. [Dissertação de Mestrado]. São José dos Campos: Instituto Tecnológico de Aeronáutica (ITA), São Paulo; 2003.

16. Kim J, Shioya M, Kobayashi H, Kaneko J, Kido M. Mechanical properties of woven laminates and felt composites using carbon fibers. Part 1: in-plane properties. Composites Science and Technology. 2004; 64: 2221-2229.

17. Varley RJ, Hodgkin JH, Simon GP. Thoughening of a trifunctional epoxy system. Part VI. Structure property relationships of the thermoplastic toughened system. Polymer. 2001; 42:3847-3858.

18. Paiva JMF, Mayer S, Rezende MC. Evaluation of compression strength after impact of carbon/epoxy composites used in aeronautical area. In: $18^{\text {th }}$ International Congress of Mechanical Engineering. COBEM 2005. November 6-11, 2005, Ouro Preto; 2005.

19. Carlsson LA, Pipes RB. Lamina compressive response. Experimental Characterization of Advanced Composite Materials. 2.ed., USA, Lancaster, Technomic Publishing; 1997. p. 81-91.

20. ASTM D3039/D3039M-00. Standard test method for tensile properties of polymer matrix composite materials. American Society for Testing Materials. [CD-ROM]; 2004.

21. Cunha JAP, Costa, ML, Rezende, MC. Influência de diferentes condições higrotérmicas na resistência à tração de compósitos de fibra de carbono/ epóxi. Porto Alegre: CBECIMAT; 2004. Avaliable from: http://www. ufrgs.br/cbecimat2004. [CD-ROM].

22. Cândido GM, Rezende MC, Almeida SFM. Hygrothermal effects on the tensile strength of carbon/epoxy laminates with molded edges. Materials Research. 2000; 3(2):11-17.

23. ASTM D3171-76. Standard test method for fiber content of resin-matrix composites by matrix digestion. American Society for Testing Materials, [CD-ROM]; 2004.

24. MEP 15-022. Technical Specification. Empresa Brasileira de Aeronáutica - Embraer; 2000. p. 36.

25. Xia Y, Ruiz C. Dynamic failure process in fibre-reinforced composites. Mechanical Identification of Composites. Elsevier Science Publishers, New York, USA; 1991. p. 213-222.

26. Masters JE. Basic failure modes of continuous fiber composites. Composites. Engineered Materials Handbook. Metals Park, OH, USA; 1987. p. $781-785$. 